\title{
PROBLEMS OF IMPROVING ARTISTIC PERCEPTION OF FUTURE ART TEACHERS
}

\author{
Kurbonova Barchinoy \\ Researcher, Ferghana State University, Ferghana, Uzbekistan
}

Article DOI: https://doi.org/10.36713/epra1820

ANNOTATION

This article examines the theoretical foundations, the nature, the essence, the social significance of artistic perception of the future art teachers. The article also describes the current state of the problem of the formation of artistic perception in the future art educators and the scientifically-pedagogical foundations of the preparation of artistic perceptions of schoolchildren for the formation of artistic perception of the students in the social needs of artistic perceptions and non-audiovisual workshops.

KEY WORDS AND PHRASES: art, fine arts, artistry, thought, perception, teacher, reader, aesthetic mind, aesthetic attitude.

\section{INTRODUCTION}

Further improvement of the continuous education system in accordance with the Action Plan of the President of the Republic of Uzbekistan Sh.Mirziyoev on "Strategy of Action for Development of the Republic of Uzbekistan in 2017-2021", approved by the Decree of the President of the Republic of Uzbekistan "On the Strategy for Further Development of the Republic of Uzbekistan" dated February 7, 2017 , increasing the quality of educational services, and continuing the policy of preparing highly-qualified cadres meeting the modern requirements of the labor market. [1].

The national program for cadres defines a set of requirements that a modern pedagog should meet. Formation of aesthetic culture at the stages of society development is an important and topical issue. It is well known that the lack of aesthetic culture is manifested in human behavior and reflects a decline in spiritual opportunities in front of his contemporaries. The strategy of the government in reforming the education system of our country is reflected in the important state documents, the main purpose of which is to educate a harmoniously developed person, to form a profound respect and interest not only for his own but also for the culture of other nations. Therefore, in front of the pedagogy, the problem of formation of aesthetic culture, first of all, is the formation of artistic components that form the basis for the development of a person, his spiritual, aesthetic and spiritual potential. Artistic perception is an emotional, analytical, integrated, systematic, and conscious learning of the content and form of the work. This process is socially significant. His orientation towards understanding, his artistry, and his abilities grow. The future art teacher has intellectual potential that requires logical, artistic-analytical, creative thinking, and the larger the potential for spiritual, aesthetic and spiritual interaction with the person can be achieved. The attributes and attributes mentioned above are the basis for the formation of an aesthetic mind - an essential aspect of the "aesthetic rich mindset" [3], and these contemporary young people are important for future artists in various fields of society.

\section{LITERATURE REVIEW}

The study of the theoretical condition of the problem allowed to summarize the close research works. A number of scientists A.I.Burov, M.S. Kagan, V.Razumny, V.K.Skatershikov studied the philosophical side of the issue. Well-known scientists N.N.Volkov and B.T.Bajanova are well aware of their work on the theory of education. L.A. Hungarian explores different aspects of perception. O.I.Nikoforova, E.V.Kvyatkovskiy, V.V.Davydov, G.Sukhobskaya explain the specific aspects of artistic perception

Philosopher, psychologist, pedagogueresearcher B.S.Meylla's studying works on artistic 


\section{SJIF Impact Factor: 6.260| ISI I.F.Value:1.241| Journal DOI: 10.36713/epra2016 ISSN: 2455-7838(Online) EPRA International Journal of Research and Development (IJRD)}

perception of as a scientific problem, about P.Y.Yakobson's artistic perception psychology, N.N.Volkov and others works we have come to the conclusion that philosophers, psychologists have studied the social significance of the artistic process, the value of artistic works and their evaluation, but the artistic perception of scientific staff. The process has not been studied. When we talk about the perception of fine art, they are not sufficiently studied in psychological and pedagogical content.

There are also some attempts to solve the problem in our country. Uzbek scientists have contributed to the development of aesthetic education, in particular, the art of education.

This problem has been revealed in Uzbekistan in the process of familiarizing students with the artistic values of Aesthetic and aesthetic education in the works of M.Aliev, A.Muminov, S.Shermukhamedov in Uzbekistan. In the works of BK Kadyrov different aspects of art education were demonstrated, and monographs by S.K.Annamuradova and S.H.Fayzullina presented the methodological aspects of studying works of art. N. Akhmedov, N. Kevish, R. Mukha-medova, N.Svichinskaya, A. Sulaymanov, Sh.Halikova focused on the problems of artistic perception in their works.

However, these authors did not intend to use the artistic-analytical study of fine arts, including their intentional or artistic perception of art.

\section{RESEARCH METHODOLOGY}

In the course of the research were used scientifically-philosophical principles and methods such as systematics, theoretical-deductive conclusions, analysis and synthesis, history and logic, hermeneutic analysis, inheritance, universalism and nationality, comparative analysis.

\section{ANALYSIS AND RESULTS}

Artistic perception of art is designed not only to get acquainted with the conceptions of the concept described in it, but also to enjoy simple sentimental and emotional excitement from the situations described in the works, but also to logical understanding and functional analysis of this simple spiritual situation. The language of artwork, its understanding of its features is an important part of understanding. Only then is the idea of the author, the artistic expression expressed in the artist's work.

At the same time, two goals are identified in the artistic perception: what is illustrated and understood. For this purpose, it is necessary to understand the composition and other components of the art form, including plasticity, structure and color.
Understanding the masterpiece of the master talking to us is the basis of artistic perception [4].

Artistic perception of the objectivesubjective content of the realistic being expressed in the artistic work requires the activeness of the human imagination.

Understanding of the meaning of symbols, requires considerate thinking and purposefulness. The artistic perception requires the artistic-analytical analysis, thinking, the language of art that is necessary for understanding the works of "imaginary space", artistic conditionality, and the means of understanding the images. In addition, artistic perception requires understanding of the artist's thoughts, views, feelings and emotions, his outlook, and so forth in his work, his sense of conformity with his life, and emotions in the audience [5].

So, artistic perception means the discovery of innovation, the human and the society in the life. A figurative artistic image is a living model that will make him feel excited.

The role of national, universal values, spiritual-educational factor in improving the quality of pedagogical staff training, the concept of state educational policy on the necessity of "creating aesthetic rich world outlook" in students.

Organizational and pedagogical aspects of the formation of artistic perception of future artists need to be accurately reflected in the targeted and constructive orientation of the work outside the university and outside the classroom. First of all, we refer to a specific pedagogical system in which it is important to intensify student motivation and artisticanalytical thinking in the process of perception of fine arts. We consider artistic analytical thinking not only as a factor in the development of certain professional knowledge, but also as a factor in improving the quality of one's personality, first of all, its intellectualcreative potential and spiritual-aesthetic qualities.

Future art teachers will be able to define the following elements in the artistic process formation process:

- goals and objectives; the process itself, its contents, main parts and structure; psychological and pedagogical conditions; methodical recommendations;

- Key parts of the process;

-psychological and pedagogical conditions, forms, methods of influence on teachers-studentspupils. perception

Purpose: to develop students' artistic

Functions:

1) Formation of art knowledge of students;

2) ability to develop logical-analytical, structural-functional artistic perception with the development of ideological, aesthetic and spiritual 


\section{SJIF Impact Factor: 6.260| ISI I.F.Value:1.241| Journal DOI: 10.36713/epra2016 ISSN: 2455-7838(Online) EPRA International Journal of Research and Development (IJRD)}

potential of works of fine art; as well as activation of thought through the comparative study of works;

3) To direct the knowledge, skills and abilities acquired to the understanding of other artistic works [6].

These tasks require a number of issues.

For example, Task 1 is to introduce the students the essential role of artistic perception in their future profession, the disclosure of their perspectives, expanding the students' artistic knowledge, understanding the artistic perceptions, and the methods of outreach activities.

Task 2 is Explaining to students what is "artistic perception", "artistic thinking" and other concepts; exemplary perception, artistic thought; acquaintance with basic requirements and fundamentals of artistic perception; Theoretical and applied work and artistic perception (under the teacher-led and independent); to acquaint students with the understanding of visual artwork and notes for analysis.

Task 3 is an attempt to capture the knowledge, skills and abilities of artistic perception and other types of art, to be analyzed. In addition, the third task includes the transfer of knowledge, skills and skills to the future pedagogical practice.

Students should discover the beauty of the world of fine arts, the need for artistic perception, the ability to do so, and to strive for their perfection; Everyone realizes that they can know and love art, learn how to read this art language, penetrate deep into the artist's perspective, realize the incomparable beauty of the real work of art, understand the beauty, feel good, and perceive strongly. Students will be able to create the brightest, most exciting, inspirational, and energetic scenery of the fine arts; its inspiration; In art, you need to learn to look beautiful in color to see and understand beauty better; they are convinced that life is exciting, joyful, meaningful, and empowering, and that they have better professional training [7].

The emotional acquisition of the vital reality of existence, and the artistic perception are of high aesthetic feelings associated with aesthetic pleasure in the perception. Understanding the world, understanding the language, understanding the meaning, understanding the form and the orderliness of the work, reflecting life, understanding the shape (as a system of symbols and embodiments), "how the work is done", how it has been constructed; The audience enjoys aesthetic pleasure from the artistic talent and skill that draws closer to the work, draws its appreciation and appreciation to the value of the artist. At the same time, the proportion of emotional and rational aspects of human intellectual level, mentality is important.
Analyzing and interpreting works of art is a complicated process, in which the associative, vital and artistic experience plays a special role. Therefore, it is possible to have subjective approach in interpreting literary works (though only pure subjective subtext [8].

Return to form and content from the form (in this process the process of understanding the essence of the work, the essence of the work, and then the process of returning from the essence), in order to restore the generalized image, which includes a whole series of artistic images and, ultimately, the whole work, the artistic component of artistic comprehension is one of them. The way back to form and content form to the way of creative cooperation to understand the secrets of the work's design. Thus, the structure is functionalized.

He engages in artistic activities such as a perceptive artist (director, conductor, actor, and restorer). The perceptive creator is creative with the author, realizing that he understands the essence of the author and the meaning of the essay and its ideological significance (under the influence of individual-imagination). In general, the creative idea of the preceptor in the artistic perception process is the creative collaboration: the ability of this creative collaboration to feel satisfied with it.

Studying the problem of higher education institutions in Uzbekistan has shown that: the use of artists' works reflects the efforts of future artists to create an artistic perception. Teachers are striving to develop this process, seeking new forms, methods, methods, and tools. However, these things are happening occasionally and without systems. Studying and summarizing problems in the practice of pedagogical higher education institutions demonstrates that, on the one hand, the image of future artists in the field of fine arts is strengthened, and on the other hand, the process is being done outside of the audience. There are attempts to develop artistic perception of future artists in the future, thus promoting them more closely with world and national artistic values.

In addition, instructors, non-audiovisual art directors are not provided with methodological recommendations for non-formal art instructors on how to create a holistic perception of art, textbooks, manuals, trainings and classroom tutorials.

In the practice of higher education institutions, a number of deficiencies identified in the perception of works of fine art can be explained by the following reasons:

- Young psychology, personal characteristics, unobservability of the perception typologies of future artists;

- their free readiness for artistic perception; the target orientation of the process, the stages 


\section{SJIF Impact Factor: 6.260| ISI I.F.Value:1.241| Journal DOI: 10.36713/epra2016 ISSN: 2455-7838(Online) EPRA International Journal of Research and Development (IJRD)}

(model) of its establishment, the inadequate design of specific tasks, methods, methods, conditions and mechanisms;

- A random selection of works of fine art;

- a thorough analytical study of works of fine art, non-use of their artistic-aesthetic capacities, nonaccountability of the emotional side of perception; - synthesis;

- synthesis of synthesis - absence of analysis

- aesthetic activity to improve the artistic perception skills, lack of creative tasks analysis;

- the lack of requirements for the level of artistic perception of future artists; of fine arts;

- Unaccounted for educational opportunities

- Absence of knowledge, abilities and skills in the life, instruction in the future pedagogical activity.

Teachers of the theory of fine arts do not have scientifically-based pedagogical guidelines for future visual arts to direct teachers to a full artistic perception.

Thus, artistic perception is not merely the language of art, but the imagination of life, their own interpretation, but the revival of those images in the perception of the perception. It is important to remember:

- Realistic mastering of the essay is a combination of intellectual and emotional mechanisms;

- Artistic perception is not only creative understanding, but also an associative process (realistic and creative experience); and form;

- understanding the work in a single, content

- The artistic content and the structure of the structure require that all of their components be studied separately and in close communication and relationships.

B.S. Mikhail interprets artistic perception quite simply - "a comprehensive, systematic perception of the content and form of the work" [9].

In our research, we look at artistic perceptions of students as emotionally-aesthetic feelings, content and form, close communication with the author, active thinking, and creative thinking in the process of analysis of the work.

The following is an interpretation of the artistic perception (authorship): a direct emotional perception of the work, its logical and functional analysis, emphasizing the ideological essence, artistic features, aesthetic value and spiritual power of the work, is to study carefully [10].

In summary, it is a complex speaker system capable of changing the situation under the influence of the following objective causes, knowing the language, understanding the form as a composite structure, deeply studying the meaning and meaning of the work through the evaluation and explanatory work:

- Genre, type, character of art;

- Structure of the work;

- Individuality of artist talent;

- Specific goals set by the artist;

- Indicator (heading, perception, annotation, recommendations);

- Emotional and intellectual abilities of the work;

- Acceptance and sensitivity of perceptions;

- Intellectual development of perceptions;

- Psychological, emotional and rational sides;

- Perception of the preceptor, its excitability, level of development;

- The artistic interests of the preceptor, his moral convictions, character, age, temperament.

Thus, the artistic perception process is adapted to a specific structure of the work. It is in harmony with the style and genre of art. But for those who always perceive it is necessary to refer to it as a guide (repairing). Entry into the artistic content of the book (repairing) helps the perceiver to perceive the artistic form "read" in its entirety, the idea of the art.

\section{REFERENCES}

1. National Program for Personnel Training of the Republic of Uzbekistan // Barkamol avlod - the foundation of the development of Uzbekistan. $-T$.. East, 1998. - p 31-61.

2. The Decree of the President of the Republic of Uzbekistan. On Strategies for Further Development of the Republic of Uzbekistan / Official Bulletin / Ministry of Justice of the Republic of Uzbekistan. Tashkent: Justice, 2017. - p.112.

3. Karimov I.A. Barkamol avlod - The foundation of the development of Uzbekistan. - T: Turkey, 1996.-p.43

4. Jabborova O.M. Values in Practical Art. Materials of the scientifically-theoretical and practicalmethodical conference of teachers of the Tashkent State Pedagogical Institute. 2003. - p.346-348.

5. Mardonov Sh.Q., Jabborova O.M. Content of artistic perception of future art teachers. Scientificmethodical magazine on continuous education: 2011 № 2. p.3-9

6. Mukhamedova R.S. Main role of Pedagogics in the field learning the interests of youth to literatures:Tashkent, 2007. - p.17, Salimova R.M. The role of spirituality in the process of preparing to professions: - Ufa, 2000. - p. 17.

7. Foxt-Babushkin Yu.U. Art and spiritual life of humanity: the necessity of art to the youth. - M.: , 1982. - p.140.

8. Khasanov R.X. Aesthetical causes of art products. - T .: 1989. -p. 40.

9. Meylak B.S. Aesthetical and literatural questions/ Sb.. - L.: Writer, 1978. - p.79.

10. Poluyanov Yu. E. Sistemitized necessity of plotting art. - M., 1992. - p.108. 